
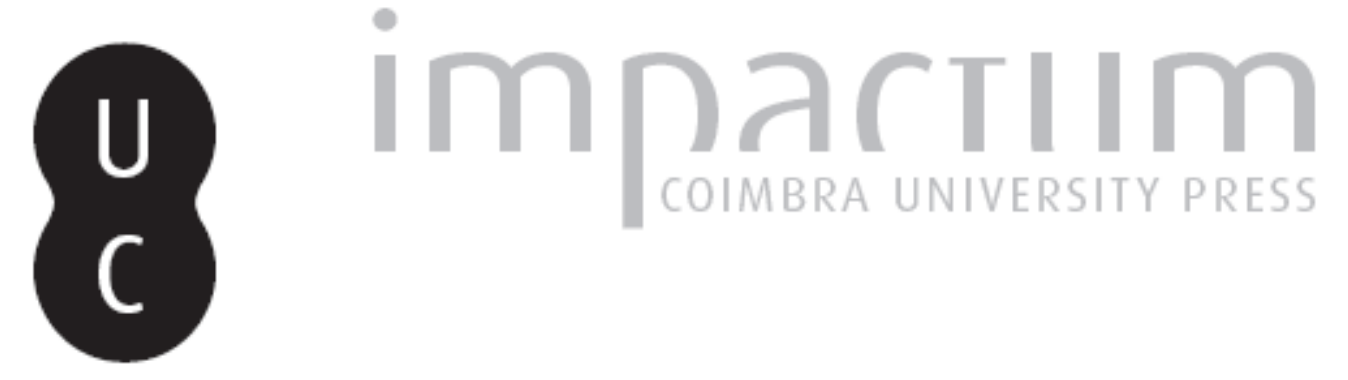

Juan Alfonso de Alburquerque: noble del reinado de Sancho IV de Castilla y León Autor(es): Kurtz, William S. Publicado por: $\begin{aligned} & \text { Faculdade de Letras da Universidade de Coimbra, Instituto de História } \\ & \text { Económica e Social }\end{aligned}$

URL persistente:

URI:http://hdl.handle.net/10316.2/33469

DOI:

DOI:http://dx.doi.org/10.14195/0870-4147_44_9

Accessed : $\quad$ 26-Apr-2023 16:33:17

A navegação consulta e descarregamento dos títulos inseridos nas Bibliotecas Digitais UC Digitalis, UC Pombalina e UC Impactum, pressupõem a aceitação plena e sem reservas dos Termos e Condições de Uso destas Bibliotecas Digitais, disponíveis em https://digitalis.uc.pt/pt-pt/termos.

Conforme exposto nos referidos Termos e Condições de Uso, o descarregamento de títulos de acesso restrito requer uma licença válida de autorização devendo o utilizador aceder ao(s) documento(s) a partir de um endereço de IP da instituição detentora da supramencionada licença.

Ao utilizador é apenas permitido o descarregamento para uso pessoal, pelo que o emprego do(s) título(s) descarregado(s) para outro fim, designadamente comercial, carece de autorização do respetivo autor ou editor da obra.

Na medida em que todas as obras da UC Digitalis se encontram protegidas pelo Código do Direito de Autor e Direitos Conexos e demais legislação aplicável, toda a cópia, parcial ou total, deste documento, nos casos em que é legalmente admitida, deverá conter ou fazer-se acompanhar por este aviso.

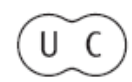




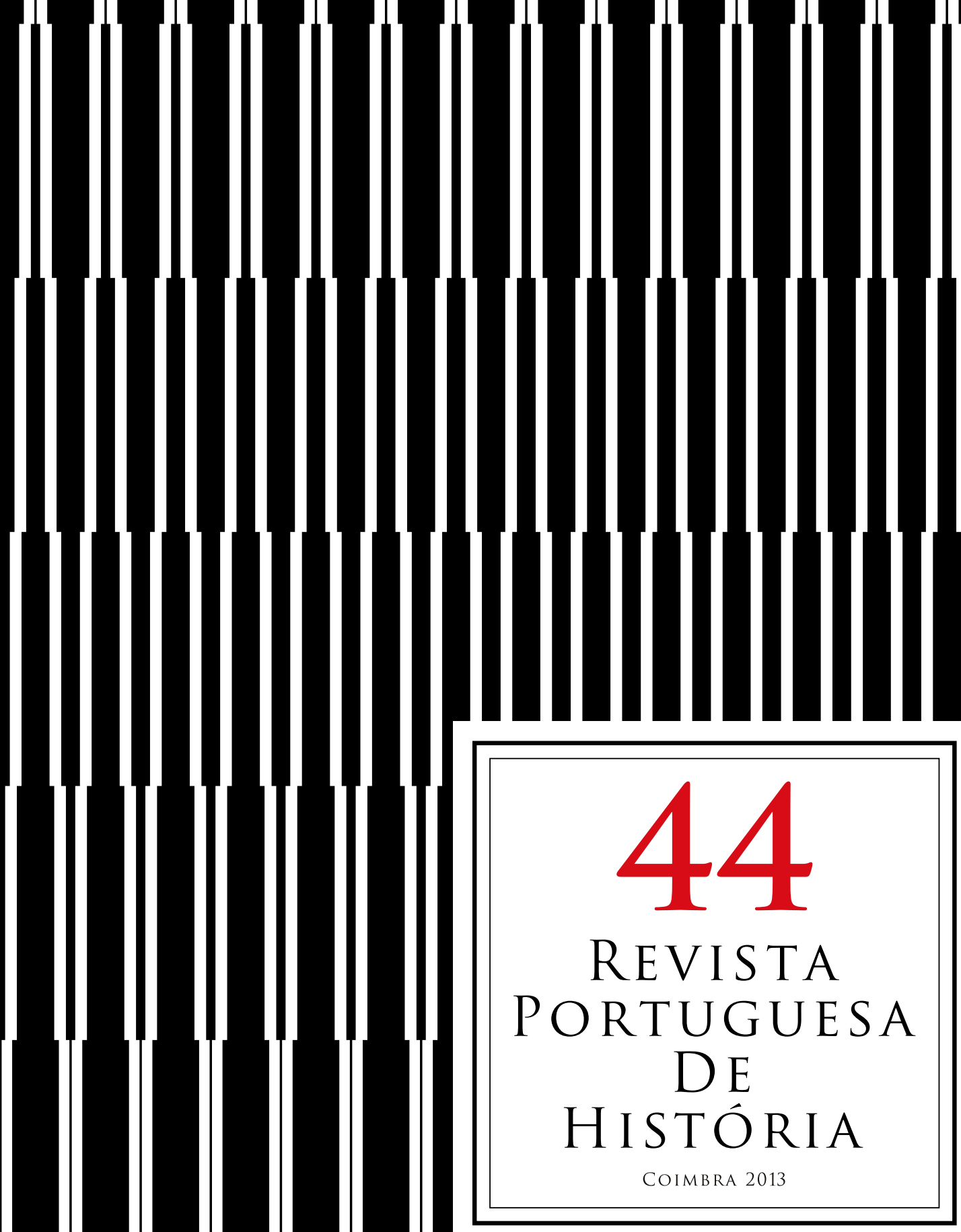




\section{Juan Alfonso de Alburquerque: noble del reinado de Sancho IV de Castilla y León}

\section{Resumen:}

Se presenta en este artículo una revisión de los documentos y datos existentes sobre la vida de Juan Alfonso de Alburquerque, señor de la villa del mismo nombre, un noble relevante de la corte de Sancho IV de Castilla y León, durante el reinado de este rey, antes de su etapa portuguesa al servicio de don Dinís. Igualmente, se replantea la interpretación tradicional, generalmente negativa, de este personaje y se propone una alternativa que se entiende como mejor ajustada a los hechos.

\section{Palavras chave:}

Juan Alfonso de Alburquerque; Sancho IV; Don Dinís.

\author{
WiLliam S. KURTZ \\ Museo Arqueológico Provincial de Badajoz \\ guillermokurtz@hotmail.com
}

\section{Abstract:}

This paper presents the early life of Juan Alfonso de Alburquerque, a prominent noble in the court of Sancho IV of Castille and Leon, before he entered the service of don Dinís of Portugal. Previous interpretations of this person have been generally negative, and the revision of extant documents and data allows for a better adjusted vision to be presented.

Keywords:

Juan Alfonso de Alburquerque; Sancho IV; Don Dinís. 
Dentro de los múltiples personajes interesantes que pueden encontrarse en el entorno de las cortes peninsulares del siglo XIII, este trabajo se centrará en la figura de Juan Alfonso de Alburquerque durante la primera etapa de su vida, aquella que transcurrió bajo el reinado de Sancho IV de Castilla-León. Es cierto que su actuación no destaca en exceso dentro del contexto de un reinado pletórico de eventos y cambios; es, al fin y al cabo, un personaje cuya acción pública tuvo una proyección y resultados más decisivos después de que abandonara Castilla-León para ponerse al servicio de don Dinís de Portugal. Mas una visión detallada de esta primera parte de su vida pública es necesaria, considero, para entender la segunda.

Además, considero que don Juan Alfonso de Alburquerque merece ser estudiado en particular por dos razones: la primera, porque en el contexto de los conocimientos comunes de la historia ha quedado postergado en beneficio de su nieto y homónimo, activo protagonista de los reinados de Alfonso XI y Pedro I. Segundo, porque desde que doña Mercedes Gaibrois le calificara, en cada una de las apariciones de nuestro personaje en su magna obra ${ }^{1}$, como perturbador, revoltoso, o algo similar, don Juan Alfonso ha cargado con el epíteto de turbulento señor, como si tal designación le fuera propio, le individualizara, como si no pudiera aplicarse a todos los nobles de la época, familia real incluida. Merece, como mínimo, la revisión de los datos históricos y documentales disponibles para dilucidar lo que de verdad pueda conocerse de él.

Debemos empezar por constatar su nobilisimo origen: descendía por estricta línea de primogenitura de Tello Pérez de Meneses; su bisabuelo fue Alfonso Téllez de Meneses, gran señor de la corte de Alfonso VIII de Castilla, reconquistador de Alburquerque y casado en segundas nupcias con Teresa Sánchez, hija ilegítima del rey Sancho I de Portugal, quien aportó su dosis de sangre real al Juan Alfonso de quien nos ocupamos aquí. Sus padres fueron Rodrigo Eanes y Teresa Martins de Soverosa, de los que la historia poco dice. Era, por derecho de nacimiento, un aristócrata, un gran señor, alguien importante. Una persona vinculada por lazos familiares a las familias reales portuguesa y castellano-leonesa (los Molina, entre ellos la futura reina doña María, descendientes de Alfonso IX de León eran primos suyos) y a las principales familias del momento, en ambos lados de la frontera. No es necesario ser excesivamente reduccionista ni determinista para pensar que tales orígenes, tal familia, tal ambiente, condicionarían necesariamente su forma de ser, su manera de estar en el mundo.

1 Mercedes Gaibrois de Ballesteros, Historia del Reinado de Sancho IV, Madrid, Real Academia de la Historia, 1922 (en lo sucesivo Gaibrois). 
Y de Juan Alfonso de Alburquerque como persona, como individuo dentro del mundo, poco más se puede colegir, porque, como ocurre con tantísimos personajes medievales, la documentación sólo nos permite conocer algo de sus actuaciones concretas, pero la persona como tal nos resulta totalmente evanescente. Por no saber no sabemos ni dónde ni cuándo nació, cómo y dónde se crió, ni en qué condiciones concretas pasó su vida más allá de las generalidades ya apuntadas. Sólo cabe añadir el dato, transmitido por los Livros de Linhagens ${ }^{2}$ de que casó, no se sabe en qué fecha, con Teresa Sánchez, hija ilegítima de Sancho IV. Descendiente de familia real, emparentado matrimonialmente con ella.

Tuvo dos hijas, al parecer legítimas, aunque tal dato no se especifica: Teresa Martíns, casada con el hijo y mayordomo mayor del rey don Dinís, Alfonso Sánchez, quien heredó el señorío de Alburquerque; y Violante Sánchez, casada con Martín Gil de Riba de Vizela, alférez mayor del mismo rey portugués. Respecto a Teresa Sánchez, su esposa, en 1300 consta otra mujer del mismo nombre, también reseñada como hija ilegítima de Sancho IV, casada con Ruy Gil de Villalobos 3 . Sería posible sacar la conclusión de que se produjo una ruptura matrimonial entre Teresa Sánchez y Juan Alfonso de Alburquerque, uniéndose aquella posteriormente con el reseñado magnate. Pero dado lo común del nombre, la escasez de información determinante y contemporánea para identificar a esta mujer y justificar suficientemente que ambas sean la misma, y la evidente posibilidad de confusión de los genealogistas por causa de la homonimia, considero que es mejor dejar simplemente apuntado este dato y no sacar conclusiones con tan pocos elementos.

La primera mención cronológica a un Juan Alfonso relacionado con Alburquerque es una concordia que el primer obispo de Badajoz, don Pedro Pérez firmó con don Alfonso Téllez (el conocido con el apelativo de Córdova) y con don Juan Alfonso el siete de julio de 1256 sobre los diezmos de Alburquerque, Codosera y Benavente ${ }^{4}$. Aparte de que este documento da una

2 Portugaliae Monumenta Historica (ed. Herculano), Scriptores, vol. I, fasc. 2, p. 157; vol. I, fasc. 3,p. 362. Pedro Salazar de Mendoza, Origen de las dignidades seglares de Castilla, Madrid, Imprenta Real 1657, p. 79b, dice que este matrimonio se celebró sin licencia del rey y justifica así la prisión posterior de don Juan Alfonso. Esta noticia parece totalmente fantasiosa.

3 Hay múltiples referencias, sólo referencias, al tema: Luis de Salazar, Historia genealógica de la Casa de Lara, Madrid, Imprenta Real, 1697, volumen 3, p. 437. Un caso documentado de este matrimonio en: María Estela González de Fauve, La orden premonstratense en España: el Monasterio de Santa María de Aguilar de Campoo (siglos XI-XV), Aguilar de Campoo, Centro de Estudios del Románico, 1992,p. 277.

4 Juan Solano de Figueroa, Historia eclesiástica de la ciudad y obispado de Badajoz, cap. VI, $\S^{\circ} 4^{\circ}$, párrafo 359 (estando inmediata a entrar en prensa la edición de esta obra que prepara el Dr. Francisco Tejada Vizuete, que se convertirá en la referencia canónica a la misma, prefiero 
idea de la extensión del señorío de Alburquerque en tal fecha, no parece que el Juan Alfonso a que se refiere sea el personaje que nos ocupa, sino que puede ser su abuelo homónimo, o incluso Juan Alfonso de Molina ${ }^{5}$.

La primera aparición documental constatada de Juan Alfonso de Alburquerque se da en documentos emitidos por Sancho IV en agosto de 1284 durante su primera estancia como rey en Sevilla, presencia que tenía la finalidad de recibir la adhesión de, o hacer las paces con, el conjunto de nobles que se habían mantenido fieles a Alfonso X hasta su muerte. Concretamente la primera aparición de don Juan Alfonso de Alburquerque (con esta denominación) se produce en la lista de confirmantes de documentos reales, el día 10 de dicho mes $^{6}$. A partir de dicha fecha, aparece constantemente en estas listas. El hecho de estar allí, junto al nuevo rey, es un dato que no ha sido valorado suficientemente. Primero, porque la lista de confirmantes de la documentación real se renovó como tal lista en este momento (durante el verano de 1284) respecto a la imperante en los últimos años del anterior monarca, incluso reaparece como tal listado pues en la numerosa documentación de la cancillería de Sancho durante la rebelión no era frecuente contar con confirmaciones. Segundo, y dado que don Juan Alfonso no aparece en ninguna documentación del reinado alfonsí, no puede deducirse que fuera alguno de los nobles leales a Alfonso que se incorporaron a la corte sanchista. Debemos, pues, inclinarnos a pensar que fuera alguna de las personas nuevas que, de entre sus fieles, Sancho IV incluyera entre los confirmantes.

Se interprete como se interprete, el hecho es que nuestro personaje aparece en la lista de confirmantes de documentos reales desde agosto de 1284, lo que indica que claramente no estaba enfrentado ostentosamente al rey sino que en algún grado gozaba de su favor. Lo que a su vez contradice el discurso general de la historiografía todavía imperante, que establece que muerto Alfonso X, don Juan Alfonso de Alburquerque se levantó contra Sancho junto con el infante don Juan para defender los derechos de éste al reino de Badajoz que le habían sido otorgados en virtud del testamento paterno. Es más, este discurso propugna que la razón de que Sancho IV pasara a Badajoz desde Sevilla en septiembre de 1284 fue acabar con la rebelión del don Juan Alfonso turbulento.

no citar por ninguna edición ya existente, por lo que cito por el manuscrito conservado en el archivo catedralicio de Badajoz).

5 El documento no da pistas sobre cuál de ellos pudiera ser. Dada la fecha, no parece que sea quien nos interesa aquí.

6 Diego Ortiz de Zúñiga, Anales Eclesiásticos y Seculares de la Muy Noble y Muy Leal Ciudad de Sevilla, tomo I, Madrid, Imprenta Real, 1795, p. 355-6. 
Esta reconstrucción de los hechos, seguida por doña Mercedes Gaibrois y a partir de ella por todos los investigadores que de una forma u otra han mencionado el tema, aparece por primera vez en 1650 y se debe a Fray Francisco Brandão. En su quinta parte de la monumental Monarchia Lusitana ${ }^{7}$ el historiador portugués, apoyándose en la unión entre el infante don Juan y nuestro personaje durante los eventos, que veremos, de 1293, y en el testamento del caballero de Guimarães don Gomes Gonçalves, realiza esta lectura de los hechos. No puede achacarsele impericia, pues su narración resulta, en primera lectura, bastante coherente y desconocía la presencia del futuro conde de Barcelós en el entourage de Sancho IV en 1284. Además, su orientación protonacional de la historia, hacía que le interesara ciertamente insistir en la desafección de Juan Alfonso de Alburquerque con los monarcas castellano-leoneses desde el primer momento como paso para explicar su eventual paso al servicio del rey portugués, lo que, strictu sensu, suponía un acto de traición, traición que era necesario rebajar de categoría y justificar como necesaria.

Los datos y los hechos pueden, deben, no obstante, reexaminarse, y de ello deriva un panorama harto diferente del propuesto por Brandão.

Primero, no existe ningún dato explícito, ni a favor ni en contra, sobre una relación directa entre el infante don Juan y don Juan Alfonso, ni a principios del reinado de Sancho IV, ni durante el reinado anterior. Ciertamente no es imposible que existiera, pero no consta. Por ello, proponer que guerrearan juntos a favor de los derechos testamentarios del infante no pasa de ser una suposición sin valor demostrativo alguno; es más, puede calificarse de suposición totalmente gratuita.

Segundo, el dato más objetivo y, lo que es más importante, directo pues se conserva en la documentación original del siglo XIII, es el testamento de Gomes Gonçalves, caballero de Guimarães. Dicho documento, fechado el 8 de junio de la era de 1323 (1285), se custodia en el Archivo Nacional de la Torre del Tombo ${ }^{8}$ y el párrafo relevante que nos interesa es:

item mando quinhentos maravedis daquela moeda que foy feita na guerra que dizem dos brancos, por aquellas malfeitorias que foron feytas nas guerras e nos roubos entre Badalhouce e Alboquerque se ante don Johan Affonso estas malfeytorias non pagar e dem estes quinhentos

${ }^{7}$ Fray Francisco Brandão, Quinta parte da Monarchia Lusytana, Lisboa, Paulo Craesbeeck, 1650, fol. 102r-v: Capit. XXXXII: Das guerras entre Badajoz, e Alburquerque, e outras acçoês del rey dom Dinis.

8 Archivo Nacional Torre del Tombo, PT/TT/MSMAR/GIM11/35 (=ANTT, CR Mosteiro de Santa María de Arouca, gaveta 5, maço $11 \mathrm{n}^{\circ}$ 3). Es consultable en línea: http://digitarq.dgarq. gov.pt/details?id=4500250, consultado 26/XII/2012. 
mrs a aqueles que souberem cuio foy e a quien ende sobeiar deno pola alma daqueles de que ouvemos o al. ${ }^{9}$

El documento revela, en primera instancia, la existencia de guerras e roubos entre Badajoz y Alburquerque; que en ellas participó, además del testador, don Juan Alfonso; y que ambos (o, entre ambos) tenían la obligación de pagar 500 maravedís por las malfeitorias acaecidas en dichas guerras. No especifica los motivos, la naturaleza, ni la fecha de la guerra, que estrictamente sólo puede inferirse tuvo lugar antes de junio de 1285.

Quisiera llamar la atención sobre los 500 maravedís. Este pago, ateniéndonos al texto, sólo admite una interpretación, el de ser una compensación por los daños infligidos durante la guerra; y las compensaciones de guerra, es una norma universal, sólo las pagan los derrotados ${ }^{10}$. De ello se deduce que don Juan Alfonso y Gomes Gonçalves perdieron esta guerra contra Badajoz.

Ahora bien, ¿qué guerra?. Visto que en agosto de 1284 don Juan Alfonso está lo suficiente bien considerado en la corte de Sancho IV como para aparecer en la lista de confirmantes de su documentación oficial, es necesario fechar la guerra en algún momento anterior. Lo que deja como única opción la que Sancho IV libró contra Badajoz entre 1282 y la muerte de su padre en 1284, guerra sufientemente atestiguada por las crónicas y por documentación independiente:

- en la Crónica de Alfonso $\mathrm{X}^{11}$ se especifica e llególe (al infante don Sancho) y (a Córdoba) mandado de cómmo se le alçara la villa de Badajoz... e él fuése para allá... et el leuó consigo a don Diego et a don Aluaro et a todos los otros rricos omnes et quando llegó a Badajoz non lo quisieron acoger et tornóse para Mérida. Lo que debió ocurrir en septiembre de 1282 según testimonia una carta enviada por el infante rebelde al concejo de Burgos desde las Viñas de Badajoz $^{12}$, desde donde se retiraría a Mérida ${ }^{13}$ unos días después.

9 Lectura propia, ligeramente diferente de la presentada por Brandão, loc. cit. supra.

${ }^{10}$ No he encontrado datos ni estudios sobre el pago de compensaciones de guerra en época medieval en la Península Ibérica, más allá de trabajos sobre el wergeld en la alta edad media norte-europea, que no vienen al caso. Curiosamente, no mencionan el tema ni el Fuero Juzgo ni el extenso repertorio de normativa legal alfonsí. El testamento de Gomes Gonçalves es, por ello, un precioso testimonio sobre el tema.

${ }^{11}$ Capítulo LXXvi, ed. de Manuel González Jiménez, Real Academia Alfonso X el Sabio, Murcia, 1968, (en lo sucesivo $C A X)$, p. 225.

12 Manuel González Jiménez, “Sancho IV, infante”, Historia, Instituciones, Documentos 28, 2001, p. 207, doc. 214.

${ }^{13}$ González Jiménez "Sancho IV ...”, p. 207, doc. 215. 
- dicha guerra seguía en marcha en diciembre del mismo año, y se especifica claramente que es una guerra contra... Badajoz, Sevilla y otras villas... ${ }^{14}$.

No he podido localizar referencias directas posteriores a la guerra en Badajoz, mas sí considero que la siguiente es una referencia indirecta: en el capítulo CCXLV de la Continuación de la Crónica de España del Arzobispo don Rodrigo Jiménez de Rada por el obispo don Gonzalo de la Hinojosa ${ }^{15}$ se narra cómo poco antes de morir, posiblemente en la primavera de 1284, don Alfonso $\mathrm{X}$ embió a Mérida á su fijo don Juan, e á don Ferrand Pérez Ponce, e á don Alvaro, e á don Juan, batisala, que fuesen sobre Mérida e que llevasen toda la mesnada, e ellos fueron sobre ella, e á cabo de ocho dias que y llegaron, entraron la villa, e la gente metióse en el alcázar, e tomáronles en la villa cuanto avian, e los fijos e las mujeres. E ellos asy estando encerrados en el alcázar e combatiéndoles de cada dia, dixeron los del concejo al Comendador que les ficiese alguna pleytesía; sy non, que ellos que non podian más estar, que avian perdido cuanto avian, e las mujeres, e los fijos, e que querían catar manera cómo se pudiesen cobrar; e el Comendador vido sus intenciones, e díxoles que atendiesen fasta otro dia e que les respondería. E otro dia el cauallero armóse e paróse á la puerta del castillo, e allí lo mataron, e luego que fué muerto, dieron los vecinos el alcáçar al infante don Juan, e él entró en él e lo tenia por suyo. E de alli destroia don Juan e los otros la tierra de enderredor que era de parte de don Sancho.

Entiendo que si Alfonso X envió un ejército para recuperar Mérida es porque estaba en condiciones de ganarla, que no necesitaba tal ejército para otras cuestiones, y que por ello tenía segura la plaza fuerte de Badajoz (que le era fiel desde $1282^{16}$ ). Esta operación puede interpretarse como una contraofensiva, por lo que obviamente había desaparecido la necesidad de mantenerse a la defensiva. Poco más puede inferirse de la noticia que aporta esta crónica, pero tomado conjuntamente con la deducción de que don Juan Alfonso perdió la guerra entre Badajoz y Alburquerque tiene sentido la siguiente reconstrucción alternativa de los hechos:

${ }^{14}$ González Jiménez, "Sancho IV ...,", p. 207, doc. 224.

${ }^{15}$ Colección de Documentos Inéditos para la historia de España 106, Madrid 1893, p. 35-36

${ }^{16}$ En los manuales es normal que se diga que Badajoz apoyó en primera instancia la rebelión de Sancho contra su padre y que inmediatamente se volvió atrás. No es imposible, pero tampoco existe testimonio alguno de dicho hipotético apoyo inicial, salvo el uso en la $C A X$ de la expresión se alçara la villa de Badajoz. Puede argumentarse perfectamente que Badajoz se mantuvo fiel en todo momento a la legitimidad alfonsina. No así su obispo, don Gil (W.S. Kurtz, "Don Gil, obispo de Badajoz", Pax et Emerita 6 (2010), p. 352-353), muy activo en la convención de Valladolid y en diferentes momentos de la rebelión sanchista. 
- iniciada la rebelión sanchista, y pronunciada la ciudad de Badajoz por el rey Alfonso X, fue atacada por Sancho IV y sus fuerzas.

- don Juan Alfonso de Alburquerque, con apoyo portugués luchó a favor de Sancho IV en esta guerra atacando desde su villa el territorio de Badajoz. Tal apoyo a la causa rebelde es coherente con el mayoritario alineamiento de la alta nobleza en las filas del infante.

- las fuerzas alfonsíes y badajocenses derrotaron a las fuerzas sanchistas en Badajoz, de ahí la imposición de la obligación de pagar reparaciones de guerra (los 500 maravedís que menciona Gomes Gonçalves) ${ }^{17}$.

- Alfonso X pasó al contraataque conquistando Mérida.

Considero que esta secuencia encaja bastante mejor con los datos disponibles, con la lógica de los hechos en una guerra civil, y no introduce, como hizo Brandão, elementos nuevos como el hipotético alineamiento de don Juan Alfonso con el infante don Juan. Por tanto, se propone como una mejor aproximación a la reconstrucción de los hechos acaecidos en la guerra civil de 1282-1284 en esta zona.

Desde esta perspectiva, la valoración de don Juan Alfonso de Alburquerque cambia radicalmente: de ser un señor permanentemente enfrentado a Sancho IV pasa a ser un personaje del entorno directo del nuevo rey (que a fin de cuentas era, o llegó a ser, su suegro), a quien apoyó militarmente en su rebelión contra Alfonso X.

Hay más datos para confirmar que don Juan Alfonso era bienquisto de Sancho IV en estas primeras fechas de su reinado: el 23 de diciembre de 1284 el rey da la orden de pago siguiente: A don Juan Alfonso de Alborquerque los mrs que montasen en Alborquerque la moneda forera ángelos a dar Pero Andrés e Martín Peres Caraço ${ }^{18}$; y en algún momento de 1285 esta otra: Sancho pérez Juiz dalua auie a pesquirir sobre los pechos encubiertos déla martiniega

${ }^{17}$ Puede argumentarse que en esta derrota tuvieron un papel las órdenes militares de Calatrava y del Temple, con territorios linderos al de Badajoz, el primero al norte y el segundo al sur; toda vez que Garcí Fernández, maestre de Calatrava, se mantuvo fiel en todo momento a Alfonso X, como muestra el que aparezca en las listas de confirmantes de la documentación emitida en Sevilla durante la rebelión sanchista en 1283 y 1284 (Manuel González Jiménez, Diplomatario Andaluz de Alfonso X, Sevilla, El Monte, 1991, docs. 508, 515 y 520). El Temple, sublevado en principio a favor de Sancho, cambió de bando tras la excomunión papal del bando rebelde y la llegada a España de don Juan Fernández, teniente del Maestre Mayor en Castilla, León y Portugal; aunque, al parecer, varios freires templarios portugueses encabezados por Pay Gómez Barreto habían actuado desde el principio en el bando alfonsí: el ocho de marzo de 1283, Alfonso X, devolvió al Temple las villas de Jerez de Badajoz (hoy de los Caballeros) y Fregenal, que previamente había incautado (ibidem, doc. 509).

${ }_{18}$ Archivo Histórico Nacional (Madrid), CÓDICES, L. 1009B, fol. 8; Gaibrois I, p. clviii. 
dalua e que fiziese Recodir con todos los derechos a don Johan alfonso de alborquerque $^{19}$. Está claro que de haber estado guerreando con él, el rey no le hubiera facilitado el cobro de impuestos, sobre todo no el de la moneda forera que normalmente los reyes castellano-leoneses se reservaban siempre como privativo. Y en agosto de este último año estuvo junto al rey en el cerco de Jerez, donde, junto con su esposa Teresa Sánchez (quien hace su primera aparición documental) intercambia propiedades y bienes con la Orden del Hospital ${ }^{20}$.

No hay, ciertamente indicios de alejamiento entre nuestro personaje y el rey. Bien al contrario. Incluso el hecho de que fuera la orden del Hospital con quien realizara el pacto de intercambio de bienes es indicativo, pues tal orden y su prior en Castilla y León, fray Fernand Pérez, se significaron considerablemente en el apoyo a la rebelión sanchista ${ }^{21}$. Tampoco hay que descontar, para explicar este acuerdo con los sanjuanistas, el factor de que el señorío de Alburquerque lindaba directamente con el territorio de la sede nuclear de la Orden de Ancántara, y que don Juan Alfonso tendría interés en contar con aliados contra sus vecinos, que por el mero hecho de serlo debían ser considerados enemigos potenciales. Y para la Orden del Hospital, contar con aliados vecinos de una orden potencialmente rival, también debió ser un factor tenido en cuenta. Bien es verdad, que de esto no se habló en el documento, más allá de muy genéricas e inconcretas promesas de apoyo mutuo.

Este último documento citado da pie a considerar las propiedades y señoríos que controló don Juan Alfonso, los que documentalmente están atestiguados solamente que no son muchos y que probablemente representen una pequeña parte del total de sus bienes ${ }^{22}$.

${ }^{19}$ Archivo Histórico Nacional (Madrid), CÓDICES, L. 1009B, fol. 29v; Gaibrois I, p. clxxvii. Se refiere seguramente a Alba de Liste.

${ }^{20}$ Archivo Histórico Nacional (Madrid), OO.MM. Carp. 575 n³ 34; Carlos Barquero Goñi, "Los Hospitalarios y la nobleza castellano-leonesa (Siglos XII-XIII)", Historia, Instituciones, Documentos 21 (1994), p. 29.

${ }^{21}$ En abril de 1282, muy al principio de la rebelión, Alfonso ya había desposeído a la orden de bienes en Carmona y Almodóvar (Carlos de Ayala Martínez, Libro de privilegios de la Orden de San Juan de Jerusalén en Castilla. Siglos XIII-XIV, Madrid 1995, docs. 359 y 361); al mes siguiente el infante por los servicios que vos don frey Fernant Pérez prior de lo que a la Horden del Hospital de Sant Jahan en Castiella e en León ... fezistes a los reyes onde yo vengo e a mí les devolvió Serpa, Mora y Nodar (ibidem, doc. 361), y, ya rey, en agosto de 1284, confirmó todos sus privilegios.

${ }^{22}$ El patrimonio familiar de los Téllez de Meneses fue grande, mas falta un estudio detallado que lo defina y cómo se repartió entre las distintas ramas de los Téllez y de los Molina. Una aproximación primera en Modesto Salcedo Tapia, "Vida de don Tello Téllez de Meneses, Obispo de Palencia”, Publicaciones de la Institución Tello Téllez de Meneses 53 (1985) págs. 79-266. 
En primer lugar, está claro que era señor de Alburquerque, territorio que englobaba las poblaciones de Benavente y La Codosera según sabemos por el ya mencionado convenio de 1256 con el obispo de Badajoz. A este territorio añadió, en 1289 (como ya se verá más adelante) el castillo de Azagala. También se ha mencionado el testimonio de las cuentas de Sancho IV de 1285 por el que se deducía que algún derecho tenía sobre Alba, casi seguramente Alba de Liste que formaba desde hacía tiempo parte del patrimonio familiar. Por el ya mencionado intercambio de bienes con la orden hospitalaria, recibió Cevico de la Torre a cambio de propiedades suyas en el entorno de Monforte de Lemos. Un curioso apunte en los libros de cuentas de Sancho IV de 129423 parece indicar que en algún momento poseyó el enclave de Zafra, Halconera y Los Santos de Maimona, aunque esta es la única mención documentada del hecho y la lectura del texto no es tan clara como sería de desear ${ }^{24}$. Por otro apunte del mismo libro de cuentas ${ }^{25}$ menciona la tierra que el rey mandó entrar que teníe don Johan Alfón de Alborquerque quando fue en su deserviçio con el infant don Johán que pasa a describir como los portazgos de Alba, Arévalo y Badajoz. De esta última ciudad es casi imposible que ostentara señorío, con lo que debe entenderse que tendría en algún momento adjudicado el cobro de este impuesto concreto; Alba de Liste ya apareció en otras fuentes y se añade al listado Arévalo, otra localidad ya vinculada al patrimonio familiar. El último dato documental procede de $1301^{26}$, cuando Juan Alfonso de Alburquerque estaba ya integrado en la corte portuguesa, por el que sabemos que este personaje tenía nombrado alcalde propio en Coria, signo inequívoco de que ejercía allí algún tipo de poder.

${ }^{23}$ Archivo Histórico Nacional (Madrid) Códices L. 985, fol. 64v (1294): Çafra e la Falconera e los Santos que disen / del infant don Johan Alfón de Alborquerque.

${ }^{24}$ Para empezar: atribuye a Juan Alfonso de Alburquerque el título de infant, normalmente reservado a los hijos de rey (una notoria excepción es la del Infante don Juan Manuel), y cabría entender del texto que sólo de Los Santos disen que era de Juan Alfonso; además, el verbo utilizado es sumamente inconcreto en sus significados.

${ }^{25}$ Archivo Histórico Nacional (Madrid) Códices L. 985, fol. 67v: Otrosí dis que recabdó Alfón Godines de la tierra que l el rey mandó entrar que teníe don Johan Alfón de Alborquerque / quando fue en su deserviçio con el infant don Johán esto / que aquí dirá / el portadgo de Alva ccc lxxx mrs / del portadgo de Arévalo e de las calo/ñas que recabdó Ferrant Martines de Arévalo porél_mil ccc / Del portadgo de Badaiós que recab/dó Gonçalo Peres de Badaiós ome de Alfón / Godines_mil xxviii mrs.

${ }^{26}$ Jose Luis Martín Martín, Documentación medieval de la Iglesia Catedral de Coria, Ediciones Universidad de Salamanca, Salamanca 1989, doc. 49. 


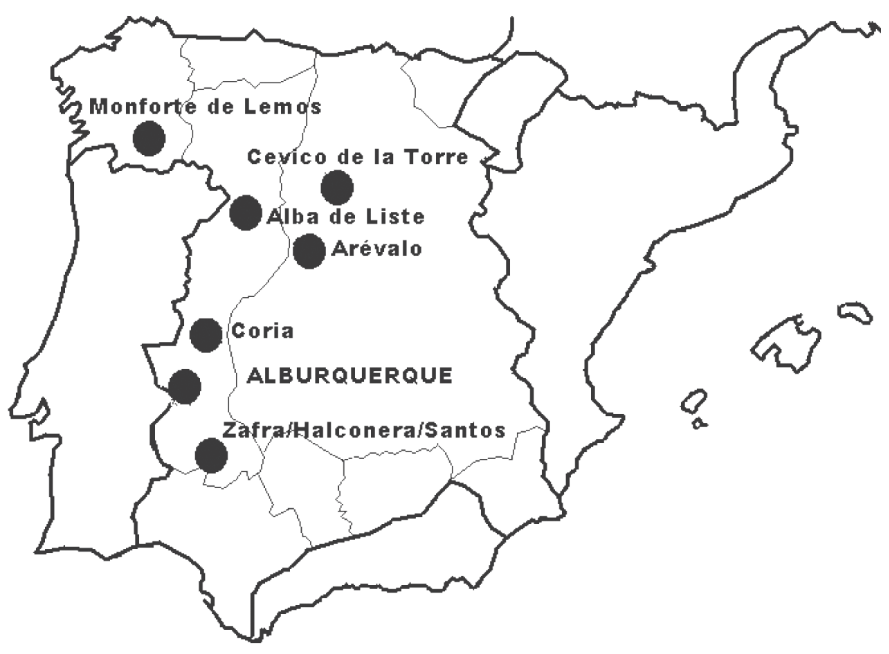

El listado de bienes, propiedades o señoríos tiene una primera lectura obvia: salvo Cevico de la Torre y Arévalo, ubicados en el reino de Castilla, todos los demás se sitúan en el reino de León y, dentro de éste, en la zona más cercana a la frontera con el reino de Portugal, abarcando desde el extremo norte gallego hasta el extremo sur del territorio leonés. De ello se podría inferir que el personaje tendría especial interés (personal) en cuestiones que tuvieran que ver con las relaciones entre ambos reinos en tanto que naturalmente le afectarían. Como mínimo, es necesario presuponerle una gran experiencia en temas que hoy llamaríamos transfronterizos o internacionales (valgan los anacronismos), lo que seguramente algo tuvo que ver con sus gestiones, ya como conde de Barcelós, en los prolegómenos de la negociación del tratado de Alcañices.

Hasta abril de 1289, inclusive, es inútil intentar encontrar algún dato más sobre don Juan Alfonso de Alburquerque. Aparece consistentemente en las confirmaciones de documentos reales y nada más ${ }^{27}$, siempre en las columnas (cuando se puede constatar fehacientemente) de la nobleza leonesa. Es decir, una vez más se constata que no era especialmente conflictivo, al menos no para el monarca y su cancillería.

${ }^{27} \mathrm{Ni}$ siquiera consta su participación en el asedio a que Dinís y Sancho IV sometieron en Arronches (consta allí la presencia del rey castellano-leonés entre el 24 de octubre, Marius Férotin, Recueil des chartes de l'abbaye de Silos, ed. Ernest Leroux, París 1897, p. 288, y el 21 de noviembre de 1287, Gaibrois, doc. 175) al infante don Alfonso de Portugal y a Alvar Núñez de Lara, participación que sería lógica inferir dado que los territorios de Arronches y de Alburquerque limitan entre sí. 
En junio de 1289 fue nombrado por el rey Adelantado de Galicia, pero conviene quizá mejor retrotraernos unos meses para explicar el nombramiento y considerar otro factor relevante para nuestro personaje. Un año antes, en junio, el día ocho concretamente, se produjo el enfrentamiento definitivo entre Sancho IV y el conde Lope Díaz de Haro que resultó en la muerte de éste y la prisión del infante don Juan. Inmediatamente se desencadenó una guerra con Aragón, cuyo rey proclamó a don Alonso de la Cerda como rey de Castilla. No es cuestión aquí de examinar con detalle estos acontecimientos, simplemente reseñar que uno de los que deben encuadrarse en este contexto es la revuelta (hacia abril-mayo de 1289) de Badajoz en el evento más conocido como el incidente de los Portugaleses y Bejaranos, ferozmente aplastada por el rey.

No consta intervención alguna de don Juan Alfonso en estos hechos, mas, por un documento de $1292^{28}$ en el que, con motivo de ordenar que se paguen al obispo de Badajoz los derechos eclesiásticos de la iglesia de Azagala, especifica que que son derechos de la eglesia quando este logar susodicho era de Badaioz e quando me lo dió a mí el rey don Sancho por me facer honrra e mercet. Está claro que, en algún momento anterior a 1292 el rey quitó este lugar a Badajoz y se lo dio a don Juan Alfonso; considero que debe atribuirse este hecho al conjunto de castigos que Sancho impuso a la ciudad rebelde (en este caso, pérdida de parte de su territorio) y que con ello premió a un señor que le era fiel. De ello no se puede inferir que don Juan Alfonso participara directa o indirectamente en el incidente de los portugaleses y bejaranos, pero ciertamente sí que se benefició de ello.

Igualmente, su nombramiento como Adelantado de Galicia, cargo en el que sustituyó a Diego Gómez, quien tenía el título como merino mayor de Galicia ${ }^{29}$, puede interpretarse como premio a su fidelidad al rey, en un momento en el que éste recomponía su entorno (o, quizá, anacronísticamente, gobierno) tras la crisis que supuso la defenestración del conde de Haro, la guerra con Aragón y la represión interior contra diferentes $\operatorname{alzados}^{30}$.

${ }^{28}$ Gaibrois III, doc. 439; que complementa otros dos de 1291: Gaibrois III, doc. 377, en que Sancho IV ordena a don Juan Alfonso que facilite al obispo de Badajoz el cobro de los diezmos de Azagala; y Gaibrois III, doc. 377 en el que este señor ordena a su alcaide en Alburquerque que se paguen los derechos al obispo en las iglesias de Benavente, Alburquerque y Codosera.

${ }^{29}$ El cambio de denominación puede, acaso, indicar una intencionalidad en la atribución de funciones y por tanto de cambio en la gestión de las funciones del cargo.

${ }^{30}$ El tema está poco estudiado, espero poder contribuir a ello en mi trabajo en curso sobre el incidente de los portugaleses y bejaranos. 
En la documentación cancilleresca aparece con este cargo entre del 9 de junio de $1289^{31}$ y el 22 , también de junio, de $1291^{32}$, apenas dos años. Poco se sabe de su actuación en este puesto, salvo que el obispo de Mondoñedo, en diciembre $1291^{33}$, al rendir cuentas al rey Sancho de los dieciocho mil maravedís en que había arrendado el seruiço quarto de los des que me prometeron en Vilabona a que sulian chamar haro de la sacada de Mondonedo presentó carta de Juan Alfonso de Alburquerque por valor de tres mil seiscientos maravedís de dicho servicio que según el obispo el noble le había tomado por fuerza. Teniendo en cuenta que el de Alburquerque ya había cesado en el cargo, y que el obispo pudo presentar testimonio documental del pago, quizá sea necesario relativizar la acusación de expolio lanzada contra él dada su calidad de explicación ex post facto. Otras acciones concretas, documentadas, no se conocen.

Sí se dispone de una noticia cronística ${ }^{34}$ :

Et otrosí don Juan Alfonso de Alburquerque, andava alboroçándose en Gallizia por consejo de don Juan Núñez et en su ayuda. Et otrosí el rey don Deonís de Portugal, que quería desabenirse del rey. Et con estos mandaderos que ovo el rey de cada parte ovo muy grand saña et dixo: "Pues que así es que estos andan catando estas maneras contra mí, sacaré al infante don Juan, mi hermano, de la prisión et parar se ha a todo esto". Et la reina, que avía sabor de ayudar al infante don Juan, punó en lo fazer cuanto pudo. Et vínose el rey para Valladolid et mandó traer al infante don Juan del castillo de Curiel, do le tenía preso. Et desque ý llegó, soltolo de la prisión en el mes de agosto, el día de Sant Bartolomé. Et otro día perdonó este infante don Juan a todos cuantos fueron en su prisión et otrosí tomó al infante don Fernando, fijo primero heredero del rey don Sancho, por rey et por señor después de días del rey su padre et besole la mano....... Et el rey fuese para

${ }^{31}$ Ayala Martínez, Libro de privilegios... doc. 391.

${ }^{32}$ Luciano Serrano, Fuentes para la Historia de Castilla, Tomo I, Colección Diplomática de San Salvador de El Moral, Santo Domingo de Silos, 1906, p. 131.

${ }^{33}$ Enrique Cal Pardo, Colección diplomática medieval do Arquivo da Catedral de Mondoñedo, Santiago de Compostela, Consello da Cultura Galega, 1999, doc. 56 (http://gmh.consellodacultura. org/o_catalogo/ficha/f/1/).

${ }^{34}$ Crónica de Sancho IV (en lo sucesivo CSIV) cap. 1xxxvi ${ }^{\circ}$ (abril 1291-marzo 1292). Cito por la aún inédita edición crítica que ha preparado Dr. Pablo Enrique Saracino, investigador del SECRIT, Buenos Aires 2010. Aprovecho para agradecerle su amabilidad al facilitarme una copia. No obstante, en espera de esta edición, utilizo la capitulación tradicional de la Crónica de los tres reyes para facilitar la consulta. 
Gallizia a sosegar a don Juan Alfonso de Alburquerque. Et desque lo ovo sosegado, fue a Santiago en romería

Esta noticia aparentemente clara esconde algún problema que exige ser puntualizada. Antes de hacerlo, es necesario recordar que la ruptura del rey con Lope Díaz de Haro supuso un brutal cambio de alianzas, aviniéndose con don Juan Núñez de Lara ${ }^{35}$, con quien andaba enfrentado desde que éste defendiera a los infantes de la Cerda como sucesores de Alfonso X. Esta alianza fue problemática: Juan Núñez, en contra de los deseos reales, guerreó contra sus propios enemigos personales; provocó una fractura dentro del grupo de privados del rey ${ }^{36}$ y una guerra abierta entre Sancho IV y el de Lara, con derrota de las fuerzas reales en Chinchilla incluida.

El problema de este texto es la fecha que especifica, que compromete incluso el valor de la fuente como tal: en el mes de agosto el día de sant Bartolomé. Esta festividad se celebra (en la iglesia latina) el 24 de agosto, lo que concuerda con la fuente al estar documentada la presencia del rey en Valladolid en dicha fecha. Lo que no concuerda es que, por lo que indica la documentación cancilleresca, esta estancia fue posterior a su viaje a Galicia ${ }^{37}$, que tuvo lugar entre finales de junio y principios de agosto. Está claro que, una vez más, existe un error en la cronología de la crónica redactada, no se olvide, varios años después de los hechos. Una posible hipótesis que permitiría cuadrar todas las fuentes, cancillerescas y cronísticas, sería suponer que la festividad en la que tuvo lugar la liberación del infante don Juan fuera el de San Bernabé (el 11 de junio, fecha en la que la iglesia oriental celebra San Bartolomé ${ }^{38}$ ) y que el autor de la CSIV hallara en sus fuentes una abreviatura o una escritura de difícil lectura para denominar el santo de la fecha y atribuyera erróneamente a Bartolomé lo que debía haber sido Bernabé. Hipótesis incomprobable, cierto, a favor del cual sólo se puede aducir que por esas fechas de junio el rey estaba entre Burgos y

${ }^{35}$ CSIV cap. $1 x x x i v{ }^{\circ}$ (abril 1289-marzo1290).

${ }^{36}$ CSIV cap. $1 x_{x x v}{ }^{\circ}$ (abril 1290-marzo1291): contrarios a don Juan Nüñez: Don Martino el obispo de Astorga, Pay Gomez Cherino, Alfonso Godínez y Estéban Perez Florian, quienes metieron al Rey que enviase cometer pleito á don Diego, que era en Aragon, é él fízolo así; favorables a don Juan Nuñez: Diego Gomez de Mendoza, Tello Gutierrez, Justicia mayor del Rey, Fernan Perez Maimon y Juan Mathé.

${ }^{37}$ El rey estuvo en Palencia el 25 de junio (Villar García 1990, doc. 224), en Santiago el 26 de julio (Gaibrois, doc. 362), en Villafranca de Valcárcel el 8 de agosto (Gaibrois, doc. 363).

${ }^{38}$ No he conseguido dilucidar si la fiesta de San Bartolomé, en la iglesia latina, se haya celebrado en alguna fecha diferente a la del 24 de agosto, pues toda la información localizable sobre el santoral es post-trentina, o, como en el caso de la liturgia mozárabe, posterior a las reformas de Cisneros. 
Palencia ${ }^{39}$, no siendo imposible una estancia en Valladolid para el onceno día del mes. Otra posible interpretación es que la liberación del infante don Juan tuviera efectivamente lugar en Valladolid el día de San Bernabé, pero que esta liberación fuera posterior al viaje a Galicia para asosegar a don Juan Alfonso, no anterior como dice la crónica.

Es necesario destacar que la crónica no aclara el porqué tal liberación tendría efectos pacificadores en don Juan Alfonso de Alburquerque en cuanto que partidario de Juan Núñez de Lara, visto que son más las ocasiones en que aparecen enfrentados el infante y el de Lara que aquellas en que actuaron coaligados. Cabe interpretar el hecho en el sentido de que Sancho IV con esta liberación buscara más bien contentar a los partidarios del infante y a los de los partidarios restantes de los Haro, con el fin de allegarse aliados para un eventual conflicto con Juan Núñez; no contentar y apaciguar a los partidarios de éste como se desprendería de una rápida y superficial lectura de la crónica. Vistos los acontecimientos de 1293 (infra) esto situaría a Juan Alfonso de Alburquerque en el bando no de Juan Núñez, sino en el del infante don Juan. Esta interpretación contradice, hay que reconocerlo, la literalidad de lo que dice la crónica, mas parece ajustarse mejor a los hechos precedentes y subsiguientes a este evento.

Este pasaje de la crónica no es tan claro como pudiera parecer en primera lectura y contiene errores de secuencia cronológica. Por tanto, las consideraciones anteriores, aun pudiendo ser válidas, deben tomarse cum mica salis toda vez que están basadas, objetivamente, en una fuente equívoca cuando no equivocada.

El caso es que, en las fechas indicadas, Sancho IV realizó un viaje breve a Galicia donde asosegó a don Juan Alfonso de Alburquerque. Está claro que le cesó como Adelantado Mayor de Galicia ${ }^{40}$, pero no parece que tomara más acciones contra el personaje. Primero por el uso del verbo, asosegar que tiene las connotaciones positivas de "aplacar, pacificar, aquietar las alteraciones del ánimo, mitigar las turbaciones y movimientos o el ímpetu de la cólera e ira" en palabras del DRAE ${ }^{41}$. Segundo porque don Juan Alfonso siguió apareciendo en la documentación cancilleresca hasta al menos noviembre de $1292^{42}$.

395 de junio, Burgos: Luis Miguel Villar García, Documentación medieval de la catedral de Segovia (1115-1300), Ediciones Universidad de Salamanca, Textos Medievales 15, Salamanca 1990, doc. 222; 20 de junio, Palencia: Ayala Martínez, Libro de privilegios... doc. 407.

${ }^{40}$ Hasta el 21 de noviembre de 1292 no vuelve a aparecer un Adelantado Mayor de Galicia (Gaibrois II, p. 189; III, doc. 438), siendo el nuevo nombrado don Pay Gómez Chariño, de quien se hablará más adelante.

${ }^{41}$ Diccionario de la Real Academia Española.

${ }^{42}$ Sevilla, 22 de noviembre de 1292, AAVV 2006; donde por cierto aparece junto con el nuevo adelantado de Galicia, el mencionado Pay Gomez Chariño. 
Respecto a actuaciones directas, documentadas, de este señor en el momento posterior a su cese como adelantado de Galicia, sólo cabe reseñar, como ya se mencionó anteriormente, que en 1291 el rey le ordenara solventar el pleito entre don Juan Alfonso y el obispo de Badajoz sobre los derechos eclesiásticos de Azagala ${ }^{43}$; un mes más tarde el señor de Alburquerque ordenó a su alcaide que facilitara al obispo el cobro de estos derechos pero en Benavente, Alburquerque y Codosera ${ }^{44}$; no haciendo lo propio con los derechos de Azagala hasta un año más tarde ${ }^{45}$. Está claro que existía un conflicto (de naturaleza sumamente normal y recurrente entre eclesiásticos y señores) entre el obispo y don Juan Alfonso que requirió la intervención real, bastante lógica por otra parte toda vez que las dos personas pertenecían a su entorno de confianza ${ }^{46}$.

Que don Juan Alfonso siguiera confiando de algún grado de favor real viene señalado por el hecho de que participara en las vistas que sostuvieron Sancho IV y Jaime II de Aragón en Monteagudo-Ariza-Soria en diciembre de 1291" que además es el primer testimonio documental de un contacto directo entre nuestro personaje y el infante don Juan. Su nombre aparece en el elenco de nobles castellano-leoneses que prestaron juramento y pleitesía al rey aragonés como garantía del cumplimiento de los acuerdos alcanzados en estas vistas. Este elenco de personajes ${ }^{48}$ es en sí bastante interesante, pues están ausentes de él los habituales privados del rey y aparecen dos personajes generalmente complejos en sus relaciones con Sancho (y, francamente, con todo el mundo): su hermano el infante don Juan y don Juan Núñez de Lara.

Como ya se ha mencionado, don Juan Alfonso siguió apareciendo en la nómina de las confirmaciones de documentos reales hasta finales de noviembre de 1292, con lo que cabe suponer que seguía, en general, en buenas relaciones con el rey. Mas, su presencia con tales personajes en las vistas castellano-aragonesas, junto con el rumbo que tomó su actuación pública poco después, puede hacer sospechar que para entonces podría haber existido algún grado de desafección.

43 Toro, 16 de octubre, Gaibrois III, doc. 377.

${ }^{44}$ Medina del Campo, 16 de noviembre, Gaibrois III, doc. 382. El tema seguía vigente en 1298, cuando don Juan Alfonso vuelve a escribir a su alcaide sobre lo mismo: Solano, Historia eclesiástica...cap. $1^{\mathrm{o}}$, s.v. Alburquerque.

${ }^{45}$ Gaibrois III, doc. 439, noviembre de 1292, salvo error en la datación.

46 Para el obispo don Gil véase Kurtz, Don Gil... passim, para don Juan Alfonso, todo lo dicho en este trabajo.

${ }^{47}$ Gaibrois II, p. 143; Memorial Histórico Español III, p. 455.

48 Infante don Juan, don Juan Manuel, entonzes mozo, don Juan Núñez el mayor, don Juan Alfonso de Alburquerque, don Juan Fernández de Limia, don Nuño Díaz de Castañeda, don Pedro Díaz de Castañeda, un hijo de Fernán Pérez Ponce. 
Hacia el primer trimestre de $1293^{49}$ el infante don Juan, viendo que su hermano se había avenido con don Juan Núñez de Lara, huyó de la corte y se refugió con Juan Alfonso de Alburquerque. Este es el momento en el que inequívocamente puede mantenerse que el señor que nos ocupa rompió (o había roto) sus relaciones con el rey. No hay indicio alguno de porqué ocurrió esto. En el maremagnum de alianzas, contraalianzas, avenencias y desavenencias que fue la corte de Sancho IV, especialmente dentro de la muy alta nobleza y la familia real, cualquier explicación es posible. Es decir, ninguna se puede fundamentar porque cualquiera puede ser válida: lealtades personales, disgustos personale ${ }^{50}$, descontento con el decurso político, conciencia de clase, capricho incluso. Llama la atención que el detonante de la ruptura de don Juan Alfonso con la corte fuera una de las múltiples vueltas del de Lara al favor del rey, teniendo en cuenta, al decir de la crónica, que un par de años antes habría estado alboroçándose en Galicia a su favor. Fuera lo que fuera, debió ser un motivo suficientemente fuerte como para que una persona hasta entonces caracterizada por la lealtad abandonara a Sancho.

Éste debió tomarse bastante mal la desafección del señor de Alburquerque pues, cuando cayó prisionero (vide infra) quiso matarle, habiendo dado Sancho IV sobradas muestras de capacidad para avenirse incluso con rivales y enemigos poderosos y desafectos (su actitud ante la nobleza leal a su padre lo demuestra, como lo hace su relación justamente con don Juan Núñez de Lara); tengo la impresión de que lo que no aguantaba Sancho era lo que percibía como traición por parte de personas que consideraba que le eran, o debían ser, afectos: el caso señero sería don Lope Díaz de Haro, pero lo mismo puede decirse del obispo don Suero de Zamora, a quien demostró encono una vez que éste decidiera

${ }^{49}$ El único rasgo que permite fechar, muy inseguramente, esta acción es que se relata en el último párrafo del capítulo lxxxvii ${ }^{\circ}$ de la $C S I V$, que corresponde al periodo abril de 1292 a marzo de 1293. Dada la inseguridad cronológica de la crónica, es ciertamente un argumento débil. Tomado en conjunto con la aparición de don Juan Alfonso en la documentación cancilleresca, hasta noviembre de 1292, resulta, no obstante, lo suficientemente coherente como para aceptarlo como indicación provisional.

${ }^{50}$ El nombramiento de Pay Gómez Chariño como Adelantado mayor de Galicia puede haber desencadenado la reacción de don Juan Alfonso, quien, durante los meses en que el cargo estuvo libre podría haber aspirado o deseado que se le reintegrara; pero tampoco me resulta una explicación, pues normalmente Sancho IV, casi ningún rey, vuelve a ocupar un cargo con una persona a quien ha cesado previamente, lo que no siempre es signo de desafección. Por ejemplo: Pay Gómez Chariño había cesado varios años antes como almirante, y siguió con el rey. Estevan Pérez Florián es la excepción a esta regla, al haber sido nombrado dos veces como Merino Mayor de León, primero en 1283, posteriormente entre 1287 y 1289 , y finalmente entre 1293 y el final del reinado; ninguno de sus ceses supuso la desavenencia con el rey. 
retirarle el apoyo que le prestara en la convención de 1282 de Valladolid y, a lo que parece, volviera a la obediencia alfonsina; o las ejecuciones que ordenó después de la guerra de 1289 contra Aragón y los infantes de la Cerda, entre las que se incluyen justamente las de los bejaranos en Badajoz.

En la segunda mitad de 1293, en fecha indeterminable, según cuenta la crónica $^{51}$, el infante don Juan intentó avenirse nuevamente con su hermano, mas a fuzia desta abenençia moujo don Juan Alfonso señor de Alburquerque con el jnfante don Juan et con ellos seysçientos caualleros hecho que debió ser muy razonablemente entendido por el rey como un acto hostil y agresivo. Don Juan Núñez de Lara el viejo se ofreció para interceptar esta agresión, mas fue derrotado en un lugar que llaman Peleas ${ }^{52}$ y llevado prisionero a Alburquerque. Eventualmente, don Juan Núñez consiguió su libertad recurriendo al rey don Dinís y a una argucia: dió su palabra al infante don Juan de volver a constituirse prisionero si la intermediación del rey portugués no daba resultados, palabra que luego alegó ser nula por haber sido dada en condiciones de falta de libertad.

La fallida misión de don Juan Núñez de Lara no fue la única acción tomada al respecto por Sancho IV. Está claro que ordenó la incautación de los bienes de don Juan Alfonso, según testimonia una entrada de su libro de cuentas ${ }^{53}$, fechada el 26 de marzo de 1294, que menciona la tierra que el rey mandó entrar que teníe don Johan Alfón de Alborquerque quando fue en su deserviçio con el infant don Johán. Entiendo que es relevante el uso de la expresión concreta quando fue en su deserviçio, por cuanto tiende a sugerir que, en el momento de la redacción del apunte contable, don Juan Alfonso ya no estaba en deservicio del rey y aliado con el infante don Juan.

Si esta interpretación es correcta, entiendo que es una fecha ante quem válida para establecer el momento de la prisión de don Juan Alfonso de Alburquerque, hecho que narra la Crónica de Fernando IV ${ }^{54} . .$. don Juan Alonso de Alburquerque que fuera preso en tiempo del rey don Sancho, e prisieralo en

${ }^{51}$ CSIV cap. 1xxxviii ${ }^{\circ}$ (abril de 1293-marzo de 1294).

${ }^{52}$ No es imposible que se tratara de Peleas de Abajo, cerca de Zamora, dado que la CSIV especifica que el de Lara se trasladó desde la corte en Burgos a Zamora.

${ }^{53}$ Archivo Histórico Nacional (Madrid) Códices L. 985, fol. 67v: Otrosí dis que recabdó Alfón Godines de la tierra que / el rey mandó entrar que teníe don Johan Alfón de Alborquerque I quando fue en su deserviçio con el infant don Johán esto / que aquí dirá / el portadgo de Alva ccc lxxx mrs / del portadgo de Arévalo e de las calo/ñas que recabdó Ferrant Martines de Arévalo por él_mil ccc / Del portadgo de Badaiós que recab/dó Gonçalo Peres de Badaiós ome de Alfón / Godines_mil xxviii mrs.

${ }^{54}$ Crónica de Fernando IV, cap. I, Antonio Benavides, Memorias de don Fernando IV de Castilla. Tomo II, Madrid, Real Academia de la Historia, imprenta de José Rodríguez, 1860, p. 7. 
Galisia a salva fe Payo Gómez Chariño ${ }^{55}$ por mandado del rey don Sancho. E porque este don Juan Alfonso era su pariente de la reyna ella tomara gran pesar por la su prisión, pero non lo pudo escusar. Pero tanto fiso de bien, que pugnó en lo guardar de la muerte, que si por la reyna non fuera quelo estorvó, muchas veses lo mandara el rey don Sancho. Está claro que la razón de su aprisionamiento fue el actuar junto con el infante don Juan. Por otra parte, ya se ha comentado esta inquina de Sancho contra don Juan Alfonso, que la crónica resalta, en parte para volver a presentar a la reina doña María de Molina en su faceta más favorable de misericordioso freno de los violentos impulsos de su marido. Esto, claro no resta credibilidad alguna a los datos cronísticos, pues la prisión se habría producido, efectivamente la reina y el señor de Alburquerque eran primos cercanos, y todavía más cierto, la reina hizo lo posible por evitar ajusticiamientos.

La expresión a salva fe puede ser indicativa sobre cómo cayó prisionero don Juan Alfonso. Primero, puede implicar un elemento de traición, de engaño; que Pay Gómez Chariño aprisionara al de Alburquerque cuando éste se sentía seguro y sin previo aviso, teniendo la frase el sentido que se le da en el siguiente artículo (el $\mathrm{n}^{\circ} 40$ ) del fuero de Coria Qui ferir o mesar a vezino sobre salva fee o livores fezier, peche $C$ maravedí ${ }^{56}$. $\mathrm{O}$, en un sentido ligeramente diferente como el que aparece en el poema de Fernán González:

590 El sol era ya bajo, que se quería tornar;

Mandó el rey García al Conde preguntar

Si se queria a presión o sobre homenaje dar,

Que podría por solo aquesto la muerte escapar.

591 A salva fe jurando dióseles a presión,

Este segundo sentido implicaría que Pay Gómez Chariño hubiera atacado directamente a Juan Alfonso, le derrotara y que éste se entregara a salva fe, lo que elimina el factor de traición. No hay argumentos para optar entre los dos sentidos, salvo que la filología eventualmente aclare el sentido exacto de la expresión.

${ }^{55}$ La crónica dice literalmente Payo Gómez Churruchano, la corrección en Chariño resulta coherente con lo sabido de personajes de la época, en el que el Churruchano conocido era Esteban Núñez, y el Adelantado mayor, entre cuyas funciones estaría la de actuar como agente real, en Galicia lugar de la prisión, fue justamente Pay Gómez Chariño.

${ }^{56}$ Citado en Rafael Serra Ruiz, "Honor, honra e injuria en el derecho medieval español", Anales de la Universidad de Murcia. Derecho 24, 1966, p. 136, nota 4. 
Fuere como fuere, en las Cortes de Valladolid de 1295, al decir de la crónica, uno de los primeros empeños de don Rodrigo maestre de Calatrava (que debió ser quien llevó la iniciativa en el tema) y de los otros ricoshombre allí presentes ${ }^{57}$ fue conseguir la liberación de don Juan Alfonso. No especifica el porqué del interés de estos nobles en esta liberación en concreto (no parece lógico pensar que el de Alburquerque fuera el único prisionero de Sancho IV), ni porqué se podía considerar especialmente injusta su reclusión. Sólo cabe especular, pues más que como simple noticia el pasaje funciona como un micro-enxiemplo que literariamente resalta la naturaleza arbitraria y violenta de Sancho IV, la misericordia de María de Molina y, además, la ingratitud en cuanto que don Juan Alfonso, a pesar del bien recibido de la reina y del apoyo de sus compañeros de clase, les abandonó pasándose al servicio de otro rey. Esta literaturización es un problema de todas las crónicas escritas en la corte de Alfonso XI y agrupadas bajo la autoría de Fernán Sánchez de Valladolid ${ }^{58}$, que no detrae de su valor como fuente pero sí lo relativiza.

Efectivamente don Juan Alfonso de Alburquerque aparece reflejado en la documentación emitida en estas cortes, una vez más en la lista de confirmantes entre el 23 de junio y el 22 de agosto ${ }^{59}$, momento en el que desaparece (para siempre) de las listas de confirmantes de la documentación cancilleresca castellano-leonesa.

El motivo de esta desaparición es bien conocida y está sobradamente documentada: abandonó Castilla-León y se pasó al servicio del rey don Dinís de Portugal, quien le nombraría eventualmente su mayordomo mayor y primer Conde de Barcelós. Los motivos de su paso a Portugal no los especifica la crónica, que sí lo califica en términos negativos como traición: fiso pleyto e omenaje que serviría al rey siempre, mas non lo fiso, nin lo guardó e fuese para el rey de Portugal e desyrvió al rey don Fernando mucho ${ }^{60}$. Esta última frase

${ }^{57}$ La crónica cita específicamente que entraron con la reina en Valladolid el arzobispo de Toledo, los obispos de Astorga, Tuy, Osma, Ávila, Coria y Badajoz; entre los nobles a Pedro Díaz de Castañeda, Lope Rodríguez de Villalobos, Juan Fernández, y los vasallos del rey y los de sus hermanos (la crónica dice erróneamente que hijos) los infantes Enrique, Pedro y Felipe, además de los maestres de Santiago, Calatrava, Alcántara, el Temple y el Prior de San Juan.

${ }^{58}$ Fernando Gómez Redondo, Historia de la prosa medieval castellana, Madrid, Cátedra, 1998-2007, trata el tema en los volúmenes I y II de su monumental trabajo; y resume la idea en vol. IV, p. 3904-5.

59 Torres Fontes 1980, docs. III y X-XI; Argote de Molina 1588, libro II, p. 165v; y Fernández Llera 1920, p. 242.

${ }^{60} \mathrm{Tal}$ calificación no deja de resultar normal en apariencia, mas resulta llamativa, teniendo en cuenta que la crónica se escribió en la corte de Alfonso XI, donde el nieto de nuestro personaje, igualmente Juan Alfonso de Alburquerque, era un gran y poderoso personaje. Puede ser un reflejo 
es opinable, pues la actuación de Juan Alfonso de Alburquerque en Portugal, si bien sujeto a los vaivenes de los intereses de don Dinís, fue tanto de apoyo como de lucha contra cada una de las facciones en las guerras en Castilla-León durante la minoría de Fernando IV; y no lo olvidemos, el resultado final de todos estos vaivenes y guerras fue la consolidación de este último en el trono.

Don Juan Alfonso, durante las cortes vallisoletanas de 1295, debió ver el cariz que tomaba la situación política en Castilla-León, no debió gustarle y se pasó al servicio de don Dinís, junto al que aparece en diciembre de dicho año, confirmando el foral de Moura ${ }^{61}$. Es significativo este hecho, pues apenas dos meses antes, los regentes por Fernando IV habían escrito a Esteban Pérez Froyán, teniente de Serpa y Mora, para que entregase ambas poblaciones a don Dinís ${ }^{62}$, poniendo fin a un contencioso fronterizo que se arrastraba desde el inicio de los reinados de Alfonso X de Castilla y de Alfonso III de Portugal.

La presencia de Juan Alfonso de Alburquerque en este asunto (que, reconozco, puede ser mera casualidad) acaso ofrezca una pista sobre sus motivaciones al pasarse al servicio portugués: sabida es su participación en las negociaciones para la boda entre Fernando IV de Castilla y la hija de don Dinís, y cómo este acuerdo facilitó el tratado de Alcañices que estabilizaría definitivamente y pacificaría la frontera entre los dos reinos. Tal pacificación pudo haber sido su objetivo, situación necesaria para garantizar la estabilidad de su señorío de Alburquerque ${ }^{63}$; mas esta es una suposición derivada de los resultados, que no siempre se prefiguran en las intenciones y motivaciones. Es igualmente creíble que don Juan Alfonso abandonara Castilla-León por hartazgo, por sentirse inseguro, o porque estuviera personalmente más cómodo junto a don Dinís.

En lo que toca a la actuación de Juan Alfonso de Alburquerque durante el reinado de Sancho IV, nada más se puede decir. Como recapitulación final, cabe decir que la imagen que resulta de este personaje una vez examinadas las fuentes es la de un noble no excesivamente activo, alineado la mayor parte del tiempo con Sancho IV quien le premia (tampoco en exceso) con la ampliación de su territorio y con el cargo de confianza de Adelantado Mayor en Galicia. Ciertamente actuó contra Sancho IV en un momento, mas puede interpretarse tal

de tensiones internas dentro de esta última corte, en el que los redactores de la crónica no fueran especialmente afectos al de Alburquerque y quisieran con esta calificación descalificarle al arrojar sombras sobre la honorabilidad y fidelidad de su notorio ancestro.

${ }^{61}$ El 9 de diciembre, concretamente (loc. cit. nota 6).

${ }^{62}$ Benavides, Memorias de Fernando IV..., cit., doc. 33; Arbor 2008, p. 16.

${ }^{63}$ Único señorío y propiedad que menciona en su testamento: Fray Francisco Brandão, Sexta parte da Monarchia Lusytana, Lisboa, Ioam da Costa, 1672, p. 30-31; también en Archivo Nacional de la Torre do Tombo, Gavetas, XVI-1-19, que no he consultado en su versión original. 
actuación como un simple alineamiento de Juan Alfonso con una de las facciones de la corte real, todas las cuales se considerarían a sí mismas totalmente leales al rey, facción derrotada en la lucha por el poder. Es difícil ver en el Juan Alfonso histórico al turbulento señor de la historiografía moderna. Es más, y aunque esto se salga de los límites autoimpuestos a este artículo, durante el periodo portugués del personaje demostró una absoluta fidelidad al rey y una total fiabilidad, hasta el punto de que se le confiaran múltiples misiones de delicada naturaleza. Fiel y constante durante el reinado (la mayor parte) de Sancho IV, fiel y constante durante su servicio a don Dinís, la conclusión lógica, y la única que nos acerca a definir un rasgo personal, es que don Juan Alfonso de Alburquerque se caracterizaba por ser fiel y constante.

Pues la fidelidad y la constancia ciertamente son valores que en la Edad Media (realmente, en todo momento) se valoraban especialmente, más aún en el contexto nobiliario en el que nació y se desarrolló don Juan Alfonso de Alburquerque. Nuestra lectura actual del siglo XIII peninsular nos hace percibirla como una época turbulenta, lo fue ciertamente, mas fijándose con un poco más de detalle puede observarse que en la actuación de sus protagonistas primaba exactamente lo contrario de la turbulencia y la desafección. Dada su naturaleza extraordinaria, es lógico que en las crónicas se hablara más de estos rasgos conflictivos que de los ordinarios, con lo que la imagen que produce la lectura de las crónicas está ciertamente desenfocada respecto de la realidad del momento. Es más, el entorno inmediato de Sancho IV muestra una notable estabilidad y fidelidad personal: puede aducirse el caso de su relación con María de Molina (relación que antepuso a cualquier consideración política, algo inusual en un rey de cualquier época) y una buena parte de las personas que le acompañaron en su época de infante seguían con él a su muerte: Alfonso Godínez, Juan Mathé, don Martín y tantos otros.

Finalmente, considero haber mostrado suficientemente que la actuación de don Juan Alfonso de Alburquerque durante el reinado de Sancho IV de Castilla-León es coherente con lo que luego sería su servicio para don Dinís de Portugal, y que el turbulento señor castellano-leonés es una invención de la historiografía (de ambos países, curiosamente), siendo realmente la misma persona que el fiable y leal Mordomo Maior y primer Conde de Barcelós portugués. 